\title{
THE FACTOR STRUCTURE, METRICAL PROPERTIES, AND CONVERGENT VALIDITY OF THE THIRD EDITION (1999) OF THE LOCUS OF CONTROL INVENTORY
}

\author{
JOHANN M SCHEPERS \\ abo@rau.ac.za \\ Department of Human Resource Management \\ University of Johannesburg \\ LIEZL GROPP \\ Department of Industrial Psychology \\ University of South Africa \\ DJ GELDENHUYS \\ Department of Industrial \& Organisational Psychology \\ UNISA
}

\begin{abstract}
The principal objective of the study was to examine the factor structure and metrical properties of the third edition (1999) of the Locus of Control Inventory (LCI). A corollary of the study was to examine the convergent validity of the instrument. After a thorough revision and extension of the scale to 88 items it was applied to a sample of 2091 first-year university students. Particular attention was paid to the shortcomings revealed in a study by de Bruin (2004). An iterative principal factor analysis of the scale was done. The three-factor-structure previously found was substantiated by the analysis. The obtained factors were interpreted as Autonomy, External Control and Internal Control. Highly acceptable reliabilities were obtained. As far as validity is concerned it was found that Internal Control and Autonomy are strongly related to Psychological Wellness and External Control negatively to Stress Management. The implications of the findings are discussed.
\end{abstract}

Key words

Sense of Coherence, Locus of Control, Emotional Intelligence

This is the third study in a series of four concerning the development and validation of the Locus of Control Inventory (LCI). As the theoretical foundation of the LCI was given in the first study (Schepers, 2005) it will not be repeated here.

Despite the fact that the second edition (1995) of the Locus of Control Inventory (LCI) produced very promising results indeed, several shortcomings were revealed in an analysis conducted by de Bruin (2004).

To start off with, he accepted the scoring key prepared by Schepers (2004), and calculated the INFIT and OUTFIT mean squares of every item according to Rasch's (1960) model for ordered category items (de Bruin, 2004, p.17; Linacre, 2003). This was done separately for each of the scales of the LCI. He found that for Autonomy only one item did not fit the rating scale model, namely item 62. Three items of the External Control scale did not fit the rating scale model, namely items 4 , 78 and 52, and five items of the Internal Control scale did not fit the model, namely items $16,59,26,76$ and 60 . The fit of item 16 was particularly poor.

On the basis of a Rasch (1960) analysis he accepted the unidimensionality of each of the scales. Next, he assigned the items in each scale randomly to one of five item parcels, obtaining a total of 15 parcels.

Thereupon he subjected the item parcels to an unrestricted maximum-likelihood factor analysis with oblique Promax rotation. A Scree-plot suggested three factors. Accordingly three factors were extracted, and the standardised residuals were calculated. There were only two residuals greater than 0,05 , suggesting a good fit indeed. The obtained factors were very well determined with loadings varying from 0,53 to 0,82 (de Bruin, 2004, p.24).
In the light of the foregoing the LCI was thoroughly revised and extended to 88 items. Next, the extended inventory was applied to the full complement of first-year university students at the Rand Afrikaans University.

Statement of problem

The principal objective of the study was to determine the factor structure of the revised edition (1999) of the LCI and to determine its metrical properties. A corollary of the study was to examine the convergent validity of the instrument.

\section{METHOD (SECTION 1)}

Logically the study falls into two sections. The first section deals with the factor structure and metrical properties of the LCI, and the second section with the convergent validity of the instrument in association with measures of emotional intelligence, sense of coherence and self-actualisation.

\section{THE FACTOR STRUCTURE AND METRICAL PROPERTIES OF THE LCI}

\section{Sample}

The full complement of first-year university students at the Rand Afrikaans University was tested with the LCI during 2000. All incomplete records were rejected. The final sample consisted of 2091 participants, and can be considered representative of the population of first-year students during 2000. The ages of the students varied from 16 to 53 years, with a mean of 18,18 years and standard deviation of 1,41 years. As far as gender is concerned $55,4 \%$ were female and $42,4 \%$ were 
male. Missing information accounted for 2,2\%. The majority of the students were English-speaking (1012). Six hundred and ninety five were Afrikaans-speaking, and 143 spoke both English and Afrikaans. Only 128 had an African language as vernacular. Sixty seven spoke other languages and did not indicate their home language. As far as ethnic group is concerned $80,9 \%$ were White, $6,6 \%$ were Indian, 3,3\% were Coloured and 7,1\% were African.

\section{Measuring instrument}

All the items of the second edition (1995) of the LCI were carefully scrutinised and edited from a language point of view. Negative concepts were eliminated as far as possible. All the items identified by de Bruin (2004) as poorer items were reformulated, except item 16 which was probably misclassified as Internal Control instead of Autonomy. The three items rejected by Schepers' (2004) analysis, viz. Items 23, 33 and 50 were replaced by new items and the inventory was extended to 88 items.
As the procedure that was followed in the analysis of the data has been fully described by Schepers (2004) only the essential results are given here.

\section{RESULTS}

The items of the LCI were intercorrelated, and the eigenvalues of the intercorrelation matrix were calculated. These matrices, however, are too large for reproduction here. $\left.{ }^{1}\right)$ Eighteen of the eigenvalues were greater than unity, accordingly 18 factors were extracted and rotated to simple structure by means of a Varimax rotation (Kaiser, 1961).

Next, 18 subscores were formed by adding all the items with substantial loadings on a factor, together. The 18 subscores were then intercorrelated. The matrix of intercorrelations is given in Table 1.

1) Available from the author on request.

TABLE 1

MATRIX OF THE INTERCORRELATIONS OF THE SUBTESTS OF THE LOCUS OF CONTROL INVENTORY (1999)

\begin{tabular}{|c|c|c|c|c|c|c|c|c|c|}
\hline Variable & Subtest 1 & Subtest 2 & Subtest 3 & Subtest 4 & Subtest 5 & Subtest 6 & Subtest 7 & Subtest 8 & Subtest 9 \\
\hline Subtest 1 & 1,000 & & & & & & & & \\
\hline Subtest 2 & 0,409 & 1,000 & & & & & & & \\
\hline Subtest 3 & $-0,145$ & $-0,083$ & 1,000 & & & & & & \\
\hline Subtest 4 & $-0,201$ & $-0,084$ & 0,405 & 1,000 & & & & & \\
\hline Subtest 5 & $-0,240$ & $-0,194$ & 0,369 & 0,452 & 1,000 & & & & \\
\hline Subtest 6 & 0,479 & 0,334 & $-0,052$ & $-0,067$ & $-0,115$ & 1,000 & & & \\
\hline Subtest 7 & 0,526 & 0,259 & $-0,308$ & $-0,322$ & $-0,505$ & 0,330 & 1,000 & & \\
\hline Subtest 8 & 0,327 & 0,341 & $-0,088$ & $-0,113$ & $-0,165$ & 0,219 & 0,228 & 1,000 & \\
\hline Subtest 9 & 0,186 & 0,384 & 0,095 & 0,201 & 0,090 & 0,224 & $-0,010$ & 0,066 & 1,000 \\
\hline Subtest 10 & 0,472 & 0,245 & $-0,132$ & $-0,109$ & $-0,151$ & 0,480 & 0,395 & 0,181 & 0,189 \\
\hline Subtest 11 & $-0,216$ & $-0,081$ & 0,372 & 0,559 & 0,404 & $-0,095$ & $-0,354$ & $-0,134$ & 0,167 \\
\hline Subtest 12 & 0,176 & 0,298 & $-0,086$ & $-0,017$ & $-0,058$ & 0,118 & 0,051 & 0,176 & 0,147 \\
\hline Subtest 13 & 0,314 & 0,471 & $-0,084$ & $-0,144$ & $-0,168$ & 0,269 & 0,226 & 0,241 & 0,203 \\
\hline Subtest 14 & 0,459 & 0,361 & $-0,060$ & $-0,106$ & $-0,132$ & 0,390 & 0,324 & 0,229 & 0,181 \\
\hline Subtest 15 & $-0,152$ & $-0,054$ & 0,142 & 0,318 & 0,215 & $-0,049$ & $-0,163$ & $-0,139$ & 0,052 \\
\hline Subtest 16 & 0,422 & 0,308 & $-0,162$ & $-0,249$ & $-0,289$ & 0,251 & 0,362 & 0,262 & 0,055 \\
\hline Subtest 17 & 0,370 & 0,375 & 0,010 & $-0,116$ & $-0,135$ & 0,253 & 0,233 & 0,195 & 0,102 \\
\hline Subtest 18 & 0,253 & 0,122 & 0,042 & $-0,032$ & $-0,032$ & 0,198 & 0,157 & 0,119 & 0,091 \\
\hline \multicolumn{10}{|c|}{ Note. $\mathrm{N}=2091$} \\
\hline & Subtest 10 & Subtest 11 & Subtest 12 & Subtest 13 & Subtest 14 & Subtest 15 & Subtest 16 & Subtest 17 & Subtest 18 \\
\hline \multicolumn{10}{|l|}{ Subtest 1} \\
\hline \multicolumn{10}{|l|}{ Subtest 2} \\
\hline \multicolumn{10}{|l|}{ Subtest 3} \\
\hline \multicolumn{10}{|l|}{ Subtest 4} \\
\hline \multicolumn{10}{|l|}{ Subtest 5} \\
\hline \multicolumn{10}{|l|}{ Subtest 6} \\
\hline \multicolumn{10}{|l|}{ Subtest 7} \\
\hline \multicolumn{10}{|l|}{ Subtest 8} \\
\hline \multicolumn{10}{|l|}{ Subtest 9} \\
\hline Subtest 10 & 1,000 & & & & & & & & \\
\hline Subtest 11 & $-0,123$ & 1,000 & & & & & & & \\
\hline Subtest 12 & 0,143 & $-0,020$ & 1,000 & & & & & & \\
\hline Subtest 13 & 0,225 & $-0,081$ & 0,159 & 1,000 & & & & & \\
\hline Subtest 14 & 0,358 & $-0,142$ & 0,109 & 0,238 & 1,000 & & & & \\
\hline Subtest 15 & $-0,065$ & 0,252 & $-0,082$ & $-0,104$ & $-0,053$ & 1,000 & & & \\
\hline Subtest 16 & 0,251 & $-0,186$ & 0,146 & 0,243 & 0,236 & $-0,162$ & 1,000 & & \\
\hline Subtest 17 & 0,164 & $-0,072$ & 0,104 & 0,284 & 0,223 & $-0,088$ & 0,270 & 1,000 & \\
\hline Subtest 18 & 0,220 & $-0,045$ & 0,062 & 0,146 & 0,167 & 0,022 & 0,089 & 0,101 & 1,000 \\
\hline
\end{tabular}


From Table 1 it is clear that the correlations of the subscores with one another vary from moderate to low and from positive to negative, suggesting more than one factor.

Following this the eigenvalues of the unreduced intercorrelation matrix were calculated. The obtained eigenvalues are given in Table 2.

TABLE 2

EIGENVALUES OF UNREDUCED INTERCORRELATION MATRIX $(18 \times 18)$

\begin{tabular}{lccc}
\hline Root & Eigenvalue & $\begin{array}{c}\text { Percentage of } \\
\text { variance }\end{array}$ & $\begin{array}{c}\text { Cumulative } \\
\text { percentage }\end{array}$ \\
\hline 1 & 4,595 & 25,528 & 25,528 \\
2 & 2,356 & $\mathbf{1 3 , 0 8 9}$ & 38,617 \\
3 & $\mathbf{1 , 2 4 0}$ & $\mathbf{6 , 8 9 2}$ & 45,509 \\
4 & 0,991 & 5,507 & 51,016 \\
5 & 0,927 & 5,150 & 56,166 \\
6 & 0,878 & 4,878 & 61,043 \\
7 & 0,850 & 4,724 & 65,767 \\
8 & 0,778 & 4,321 & 70,087 \\
9 & 0,734 & 4,080 & 74,167 \\
10 & 0,680 & 3,777 & 77,944 \\
11 & 0,643 & 3,574 & 81,518 \\
12 & 0,628 & 3,489 & 85,007 \\
13 & 0,577 & 3,207 & 88,214 \\
14 & 0,507 & 2,819 & 91,033 \\
15 & 0,474 & 2,635 & 93,668 \\
16 & 0,409 & 2,271 & 95,939 \\
17 & 0,389 & 2,160 & 98,099 \\
18 & 0,342 & 1,901 & 100,000 \\
\hline Trace & 18,000 & & \\
\hline
\end{tabular}

Table 2 shows that three of the eigenvalues are greater than unity, suggesting three factors (Kaiser, 1961).

Accordingly three factors were extracted and rotated to simple structure by means of a Direct Oblimin rotation. The rotated factor matrix is given in Table 3 .

From an inspection of Table 3 it is clear that all three factors are well determined with four or more high loadings. Thirty-two items relating to Autonomy had substantial loadings on Factor I. Accordingly Factor I was interpreted as Autonomy. Twenty-eight items associated with External Control had substantial loadings on Factor II. Factor II was therefore interpreted as External Control. Twenty-eight items relating to Internal Control had substantial loadings on Factor III. Factor III was therefore interpreted as Internal Control.

From the intercorrelations of the factors it is clear that External Control and Internal Control are essentially uncorrelated. External Control is moderately negatively correlated with Autonomy, and Internal Control is moderately positively correlated with Autonomy.

Next, three scales were formed, corresponding to the factors obtained. These scales were then subjected to item analysis.

The means and standard deviations of the item statistics in respect of Scale I (Autonomy) are shown in Table 4.

Table 4 shows that the mean of the item means is 5,172 , which is above average, judged on a seven-point scale. The mean of the item-total correlations is 0,471 , which indicates a high internal consistency of the items in the scale. This is supported by the Cronbach alpha reliability coefficient of 0,880 . No items were rejected.

TABle 3

ROTATED FACTOR MATRIX (DIRECT OBLIMIN)

\begin{tabular}{|c|c|c|c|c|c|c|}
\hline & Variables & $\mathrm{K}$ & Factor I & Factor II & Factor III & $\mathbf{h}_{\mathrm{j}}^{2}$ \\
\hline Subtest 1: & Items $3,30,46,64,66,68,70,73^{*}, 74,81,82$ and 83 & 12 & 0,648 & $-0,139$ & $+0,156$ & 0,627 \\
\hline Subtest 2: & Items $6,7,10,27,32,37,42,48,49,61,63,75,76,78$ and 87 & 15 & $-0,080$ & $-0,004$ & $+0,916$ & 0,767 \\
\hline Subtest 3: & Items $12,34,35,36,41$ and 79 & 6 & 0,002 & 0,530 & $+0,007$ & 0,280 \\
\hline Subtest 4: & Items $4,9,45,47,50,51,57,58$ and 65 & 9 & 0,047 & 0,762 & $-0,007$ & 0,568 \\
\hline Subtest 5: & Items $20,38,43,52,53,56$ and 88 & 7 & $-0,050$ & 0,623 & $-0,077$ & 0,432 \\
\hline Subtest 6: & Items $2,5,23,24,29$ and 67 & 6 & 0,635 & 0,060 & $+0,070$ & 0,442 \\
\hline Subtest 7: & Items $1^{*}, 13,21^{*}, 39^{*}, 44$ and $71^{*}$ & 6 & 0,512 & $-0,442$ & $-0,051$ & 0,527 \\
\hline Subtest 8: & Items $8,33,40$ and 54 & 4 & 0,120 & $-0,129$ & $+0,320$ & 0,197 \\
\hline Subtest 9: & Items $18,19,26$ and 31 & 4 & 0,119 & 0,328 & $+0,381$ & 0,260 \\
\hline Subtest 10: & Items $14,15^{*}$ and 28 & 3 & 0,700 & $-0,010$ & $-0,073$ & 0,442 \\
\hline Subtest 11: & Items 72,80 and 84 & 3 & $-0,060$ & 0,672 & $+0,060$ & 0,459 \\
\hline Subtest 12: & Items 60 and 86 & 2 & $-0,030$ & $-0,006$ & $+0,348$ & 0,112 \\
\hline Subtest 13: & Items 55 and 59 & 2 & 0,075 & $-0,070$ & $+0,492$ & 0,309 \\
\hline Subtest 14: & Items $16,22,25$ and 69 & 4 & 0,474 & $-0,020$ & $+0,144$ & 0,327 \\
\hline Subtest 15: & Item 77 & 1 & 0,039 & 0,357 & $-0,086$ & 0,136 \\
\hline Subtest 16: & Items 11 and $17^{*}$ & 2 & 0,221 & $-0,265$ & $+0,234$ & 0,279 \\
\hline Subtest 17: & Item 85 & 1 & 0,146 & $-0,060$ & $+0,347$ & 0,213 \\
\hline Subtest 18: & Item 62 & 1 & 0,335 & 0,058 & $-0,005$ & 0,104 \\
\hline \multicolumn{2}{|c|}{ Number of items per factor } & 88 & 32 & 28 & 28 & \\
\hline
\end{tabular}

Note: Factor III has been reflected

INTERCORRELATIONS OF FACTORS

\begin{tabular}{|c|c|c|c|}
\hline Variables & Autonomy & External control & Internal control \\
\hline Autonomy & 1,000 & $-0,230$ & $+0,563$ \\
\hline External control & $-0,230$ & 1,000 & $-0,160$ \\
\hline Internal control & $+0,563$ & $-0,160$ & 1,000 \\
\hline
\end{tabular}

Note. $\mathrm{N}=2091$ 
TABLE 4

MEANS AND STANDARD DEVIATIONS OF THE ITEM STATISTICS IN RESPECT OF SCALE I OF THE LCI: AUTONOMY

\begin{tabular}{lcccc}
\hline & $\begin{array}{c}\text { Mean of } \\
\text { items } \\
\overline{\mathrm{X}}_{\mathrm{g}}\end{array}$ & $\begin{array}{c}\text { Standard } \\
\text { deviation of } \\
\text { items }\left(\mathbf{S}_{\mathrm{g}}\right)\end{array}$ & $\begin{array}{c}\text { Item-test } \\
\text { correlations } \\
\left(\mathbf{r}_{\mathrm{gx}}\right)\end{array}$ & $\begin{array}{c}\text { Index of } \\
\text { reliability of } \\
\text { items }\left(\mathbf{r}_{\mathrm{gx}} \mathbf{s}_{\mathrm{g}}\right)\end{array}$ \\
\hline Mean & 5,172 & 1,232 & 0,471 & 0,572 \\
$\mathrm{SD}$ & 0,456 & 0,174 & 0,093 & 0,104 \\
\hline
\end{tabular}

Cronbach alpha $=0,880$

Mean of test $=165,495$

Standard deviation $=18,293$

Number of items $=32$

$\mathrm{N}=2091$

Note. Reflect items 1, 15, 21, 39, 71 and 73

The means and standard deviations of the item statistics in respect of Scale II (External Control) are given in Table 5.

TABLE 5

MEANS AND STANDARD DEVIATIONS OF THE ITEM STATISTICS IN RESPECT OF SCALE II OF THE LCI: EXTERNAL CONTROL

\begin{tabular}{lcccc}
\hline & $\begin{array}{c}\text { Mean of } \\
\text { items } \\
\overline{\mathrm{X}}_{\mathrm{g}}\end{array}$ & $\begin{array}{c}\text { Standard } \\
\text { deviation of } \\
\text { items }\left(\mathbf{S}_{\mathrm{g}}\right)\end{array}$ & $\begin{array}{c}\text { Item-test } \\
\text { correlations } \\
\left(\mathbf{r}_{\mathrm{gx}}\right)\end{array}$ & $\begin{array}{c}\text { Index of } \\
\text { reliability of } \\
\text { items }\left(\mathbf{r}_{\mathrm{gx}} \mathbf{s}_{\mathrm{g}}\right)\end{array}$ \\
\hline Mean & 3,381 & 1,478 & 0,472 & 0,700 \\
SD & 0,733 & 0,124 & 0,094 & 0,163 \\
\hline
\end{tabular}

Cronbach alpha $=0,871$

Mean of test $=94,670$

Standard deviation $=19,606$

Number of items $=28$

$\mathrm{N}=2091$

Note. Reflect item 17

Table 5 shows that the mean of the item means is 3,381 , which is below average, judged on a seven-point scale. The mean of the item-total correlations is 0,472 , which indicates a high internal consistency of the scale. This is substantiated by the Cronbach alpha reliability coefficient of 0,871 . No items were rejected.

The means and standard deviations of the item statistics in respect of Scale III (Internal Control) are given in Table 6.

TABLE 6

MEANS AND STANDARD DEVIATIONS OF THE ITEM STATISTICS IN RESPECT OF SCALE III OF THE LCI: INTERNAL CONTROL

\begin{tabular}{lcccc}
\hline & $\begin{array}{c}\text { Mean of } \\
\text { items } \\
\overline{\mathrm{X}}_{\mathrm{g}}\end{array}$ & $\begin{array}{c}\text { Standard } \\
\text { deviation of } \\
\text { items }\left(\mathrm{S}_{\mathrm{g}}\right)\end{array}$ & $\begin{array}{c}\text { Item-test } \\
\text { correlations } \\
\left(\mathrm{r}_{\mathrm{gx}}\right)\end{array}$ & $\begin{array}{c}\text { Index of } \\
\text { reliability of } \\
\text { items }\left(\mathrm{r}_{\mathrm{gx}} \mathbf{s}_{\mathrm{g}}\right)\end{array}$ \\
\hline Mean & 5,849 & 1,087 & 0,428 & 0,457 \\
$\mathrm{SD}$ & 0,330 & 0,169 & 0,061 & 0,050 \\
\hline
\end{tabular}

Cronbach alpha $=0,822$

Mean of test $=163,768$

Standard deviation $=12,779$

Number of items $=28$

$\mathrm{N}=2091$

Note. No items to be reflected

From Table 6 it can be seen that the mean of the item means is 5,849 , which is above average, judged on a seven-point scale. The mean of the item-total correlations is 0,428 , which indicates a high internal consistency in respect of the scale. This is supported by the Cronbach alpha reliability coefficient of 0,822 . No items were rejected.
From the foregoing it is clear that the three-factor-structure of the LCI was supported, and that the scales corresponding to the three factors, have highly acceptable reliabilities.

Next, the convergent validity of the LCI in association with measures of emotional intelligence, sense of coherence and selfactualisation, were determined.

\section{METHOD (SECTION 2)}

\section{THE CONVERGENT VALIDITY OF THE LCI}

\section{Sample}

A random sample of 200 employees from the head-office of a company in the Financial Services Industry in South Africa was drawn. The population consisted of 1402 employees. The general business language of the company is English, and all the staff are proficient in English. The company only employs staff with a minimum educational qualification of matric. However, the majority of the staff have a post matric diploma or degree. The ages of the employees varied from 20 to 59 years, with a mean of 30,375 years and a standard deviation of 6,173 years. Sixty-two percent of the sample were female and $38 \%$ were male. As far as posts are concerned $17,5 \%$ were managerial positions and $82,5 \%$ were non-managerial positions. As far as ethnic group is concerned $15,5 \%$ were Black, $65 \%$ were White, $11 \%$ were Coloured, and $8,5 \%$ were Indian.

\section{Measuring instruments}

The following instruments were applied to the sample jointly with the LCI: The BarOn Emotional Quotient Inventory (EQ-ir) (Bar-On, 1997), the Sense of Coherence Scale (SOC) (Antonovsky, 1993), and the Personal Orientation Inventory (POI) (Bloxom, 1972; Knapp, 1976).

All the instruments have acceptable reliabilities and technical manuals are available for all of them as indicated above, therefore no further detail will be given here.

\section{Procedure}

All the instruments were applied to the full sample and scored according to the procedures indicated in the manuals. Complete records were obtained in respect of 200 cases.

\section{Statistical analysis}

According to Bloxom (1972, p.121) the Personal Orientation Inventory (POI) "is a self-report instrument designed to assess values, attitudes, and behavior relevant to Maslow's concept of the self-actualizing person". It contains 12 subtests and has acceptable test-retest reliabilities (Bloxom, 1972).

In order to reduce the number of scores of the POI the various subtests were intercorrelated and subjected to a principal components analysis. Two eigenvalues were greater than unity, accordingly two principal components were extracted (Kaiser, 1961). The obtained principal components were rotated to simple structure by means of a Direct Oblimin rotation and is given in Table 7.

From Table 7 it is clear that the following subtests of the POI have high loadings on the first component: Support Ratio, Acceptance of Aggression, Feeling Reactivity, Capacity for Intimate Contact, Self-acceptance, Spontaneity, and Existentialism

All these measures relate to self-actualisation in the interpersonal sphere (Bloxom, 1972, p.121). The first component was accordingly interpreted as Self-actualisation.

The following subtests of the POI have moderate to high loadings on the second component: Nature of Man, Synergy, Self-actualising Value, and Self-regard. These measures relate to 
what a self-actualised individual holds dear or important to himself/herself. The second component was therefore identified as Value Systems.

TABLE 7

ROTATED COMPONENT MATRIX (DIRECT OBLIMIN)

\begin{tabular}{lcc}
\hline Variables & Component 1 & Component 2 \\
\hline Support Ratio & $\mathbf{0 , 8 9 0}$ & 0,165 \\
Acceptance of Aggression & $\mathbf{0 , 8 6 3}$ & $-0,155$ \\
Feeling Reactivity & $\mathbf{0 , 8 4 4}$ & \\
Capacity for Intimate Contact & $\mathbf{0 , 8 4 3}$ & \\
Self-acceptance & $\mathbf{0 , 8 4 2}$ & $-0,167$ \\
Spontaneity & $\mathbf{0 , 8 2 3}$ & \\
Existentialism & $\mathbf{0 , 6 4 0}$ & 0,263 \\
Time Competence & $\mathbf{0 , 4 2 0}$ & 0,374 \\
Nature of Man & $-0,193$ & $\mathbf{0 , 8 6 3}$ \\
Synergy & 0,108 & $\mathbf{0 , 7 7 6}$ \\
Self-actualising Value & $\mathbf{0 , 4 8 9}$ & $\mathbf{0 , 4 9 6}$ \\
Self-regard & 0,262 & $\mathbf{0 , 3 5 8}$ \\
\hline
\end{tabular}

Note. Values less than 0,100 not listed.

Next, subscores were computed for each participant, in respect of each of the components, by adding the scores together of all those subtests of the POI that have high loadings on a component. Thus two scores were obtained for each participant.

\section{RESULTS}

As a first step the scores of the following instruments were intercorrelated: The EQ-ir (five composite scales), the SOC (three scales), the POI (two scales), and the LCI (three scales). The matrix of intercorrelations $(13 \times 13)$ is given in Table 8 .

Next, the eigenvalues of the unreduced intercorrelation matrix were calculated and are given in Table 9 .

From Table 9 it is clear that only three eigenvalues were greater than unity. Accordingly three factors were extracted and rotated to simple structure by means of a Direct Oblimin rotation (Kaiser, 1961). The rotated factor matrix is given in Table 10.

From Table 10 it is clear that Factors 1 and 3 are well determined with five or more high loadings. Factor 2 has two moderate loadings and two relatively low loadings.

Factor 1 has high loadings on EQ General Mood, EQ Interpersonal, LCI Internal Control, LCI Autonomy, EQ Intrapersonal, and moderate loadings on EQ Adaptability and SOC Meaningfulness.

A brief exposition will now be given of the various scales with high loadings on Factor 1.

\section{EQ General Mood}

This scale relates to one's outlook on life and general feeling of contentment. It includes the Happiness and Optimism facet scales of the EQ-ir. Individuals that measure high on Happiness and Optimism are usually cheerful, positive, hopeful and optimistic, and enjoy life. They help to generate an uplifting, and positive atmosphere in the workplace and this is a motivational component in problem solving and stress tolerance (Bar-On, 1997).

\section{EQ Interpersonal}

This scale relates to the interpersonal skills and functioning of an individual and includes the Interpersonal Relationship, Empathy and Social Responsibility scales of the EQ-ir. Persons with high scores on this scale are responsible and dependable individuals with good social skills. They interact and relate well with others (Bar-On, 1997).

\section{LCI Internal Control}

Rotter (1966) distinguished between two different orientations in people, namely an internal control orientation and an external control orientation. People with an internal control orientation are convinced that the reinforcement of their behaviour depends on their own achievements, abilities and dedication, whereas people with an external control orientation believe that random or fortuitous events, fate, Lady Luck and certain influential people are responsible for their behaviour.

TABle 8

MATRIX OF INTERCOREELATIONS OF THE SELECTED MEASURES

\begin{tabular}{|c|c|c|c|c|c|c|c|c|c|c|c|c|c|c|}
\hline Variable & 1 & 2 & 3 & 4 & 5 & 6 & Variable & 7 & 8 & 9 & 10 & 11 & 12 & 13 \\
\hline 1 LCI: AUTONOMY & 1,000 & $-0,362$ & 0,624 & 0,435 & 0,522 & 0,428 & 1 LCI: AUTONOMY & 0,688 & 0,431 & 0,453 & 0,617 & 0,607 & 0,365 & 0,176 \\
\hline $\begin{array}{l}2 \text { LCI: EXTERNAL } \\
\text { CONTROL }\end{array}$ & $-0,362$ & 1,000 & $-0,180$ & $-0,372$ & $-0,482$ & $-0,315$ & $\begin{array}{l}2 \text { LOLCI:C EXTERNA } \\
\text { CONTROL }\end{array}$ & $\mathrm{LL}-0,38$ & $4-0,175$ & $-0,497$ & $-0,426$ & $-0,231$ & $-0,224$ & 0,194 \\
\hline $\begin{array}{l}3 \text { LCI: INTERNAL } \\
\text { CONTROL }\end{array}$ & 0,624 & $-0,180$ & 1,000 & 0,284 & 0,337 & 0,434 & $\begin{array}{l}3 \text { LCI: INTERNAL } \\
\text { CONTROL }\end{array}$ & 0,452 & 0,459 & 0,303 & 0,440 & 0,411 & 0,152 & 0,118 \\
\hline $\begin{array}{l}4 \text { SOC } \\
\text { COMPREHENSION }\end{array}$ & 0,435 & $-0,372$ & 0,284 & 1,000 & 0,609 & 0,490 & $\begin{array}{l}4 \text { SOC } \\
\text { COMPREHENSION }\end{array}$ & 0,530 & 0,307 & 0,519 & 0,511 & 0,466 & 0,193 & 0,179 \\
\hline $\begin{array}{l}5 \text { SOC } \\
\text { MANAGEABILITY }\end{array}$ & 0,522 & $-0,482$ & 0,337 & 0,609 & 1,000 & 0,662 & $\begin{array}{l}5 \text { SOC } \\
\text { MANAGEABILITY }\end{array}$ & 0,640 & 0,421 & 0,596 & 0,546 & 0,586 & 0,308 & 0,280 \\
\hline $\begin{array}{l}6 \text { SOC } \\
\text { MEANINGFULNESS }\end{array}$ & 0,428 & $-0,315$ & 0,434 & 0,490 & 0,662 & 1,000 & $\begin{array}{l}6 \text { SOC } \\
\text { MEANINGFULNESS }\end{array}$ & 0,574 & 0,399 & 0,386 & 0,420 & 0,555 & 0,278 & 0,316 \\
\hline $\begin{array}{l}7 \text { EQ INTRA- } \\
\text { PERSONAL }\end{array}$ & 0,688 & $-0,384$ & 0,452 & 0,530 & 0,640 & 0,574 & $\begin{array}{l}7 \text { EQ INTRA- } \\
\text { PERSONAL }\end{array}$ & 1,000 & 0,570 & 0,540 & 0,719 & 0,822 & 0,468 & 0,294 \\
\hline $\begin{array}{l}8 \text { EQ INTER- } \\
\text { PERSONAL }\end{array}$ & 0,431 & $-0,175$ & 0,459 & 0,307 & 0,421 & 0,399 & $\begin{array}{l}8 \text { EQ INTER- } \\
\text { PERSONAL }\end{array}$ & 0,570 & 1,000 & 0,400 & 0,508 & 0,625 & 0,142 & 0,207 \\
\hline $\begin{array}{l}9 \text { EQ STRESS } \\
\text { MANAGEMENT }\end{array}$ & 0,453 & $-0,497$ & 0,303 & 0,519 & 0,596 & 0,386 & $\begin{array}{l}9 \text { EQ STRESS } \\
\text { MANAGEMENT }\end{array}$ & 0,540 & 0,400 & 1,000 & 0,736 & 0,528 & 0,109 & 0,184 \\
\hline 10 EQ ADAPTABILITY & 0,617 & $-0,426$ & 0,440 & 0,511 & 0,546 & 0,420 & 10 ADAPTABILITY & 0,719 & 0,508 & 0,736 & 1,000 & 0,623 & 0,195 & 0,204 \\
\hline $\begin{array}{l}11 \text { EQ GENERAL } \\
\text { MOOD }\end{array}$ & 0,607 & $-0,231$ & 0,411 & 0,466 & 0,586 & 0,555 & $\begin{array}{l}11 \text { EQ GENERAL } \\
\text { MOOD }\end{array}$ & 0,822 & 0,625 & 0,528 & 0,623 & 1,000 & 0,324 & 0,306 \\
\hline $\begin{array}{l}12 \text { POI SELF- } \\
\text { ACTUALISATION }\end{array}$ & 0,365 & $-0,224$ & 0,152 & 0,193 & 0,308 & 0,278 & $\begin{array}{l}12 \text { POI SELF- } \\
\text { ACTUALISATION }\end{array}$ & 0,468 & 0,142 & 0,109 & 0,195 & 0,324 & 1,000 & 0,383 \\
\hline $\begin{array}{l}13 \text { POI VALUE } \\
\text { SYSTEMS }\end{array}$ & 0,176 & $-0,194$ & 0,118 & 0,179 & 0,280 & 0,316 & $\begin{array}{l}13 \text { POI VALUE } \\
\text { SYSTEMS }\end{array}$ & 0,294 & 0,207 & 0,184 & 0,204 & 0,306 & 0,383 & 1,000 \\
\hline
\end{tabular}




\section{LCI Autonomy}

A construct closely related to internal control is Autonomy. Autonomy can be defined as "the tendency to attempt to master or be effective in the environment, to impose one's wishes and designs on it" (Wolman, 1973, p.37). It is expected that persons high on autonomy would seek control of situations that offer possibilities of change, would readily accept the challenge of solving complex problems, would take the initiative in situations requiring leadership, would prefer to work on their own and to structure their own work programme.

TABLE 9

EIGENVALUES OF UNREDUCED INTERCORRELATION MATRIX

\begin{tabular}{lccc}
\hline Root & Eigenvalue & $\begin{array}{c}\text { Percentage of } \\
\text { variance }\end{array}$ & $\begin{array}{c}\text { Cumulative } \\
\text { percentage }\end{array}$ \\
\hline 1 & $\mathbf{6 , 2 1 0}$ & 47,766 & 47,766 \\
2 & $\mathbf{1 , 2 3 8}$ & 9,521 & $\mathbf{5 7 , 2 8 8}$ \\
3 & $\mathbf{1 , 1 5 5}$ & $\mathbf{8 , 8 8 2}$ & $\mathbf{6 6 , 1 7 0}$ \\
4 & 0,812 & 6,249 & 72,419 \\
5 & 0,753 & 5,791 & 78,210 \\
6 & 0,676 & 5,202 & 83,412 \\
7 & 0,525 & 4,038 & 87,450 \\
8 & 0,424 & 3,265 & 90,715 \\
9 & 0,353 & 2,713 & 93,428 \\
10 & 0,302 & 2,321 & 95,749 \\
11 & 0,233 & 1,790 & 97,539 \\
12 & 0,202 & 1,558 & 99,097 \\
13 & 0,117 & 0,903 & 100,000 \\
\hline Trace & 13,000 & & \\
\hline
\end{tabular}

TABLE 10

ROTATED FACTOR MATRIX (DIRECT OBLIMIN - ROTATION)

\begin{tabular}{lcccc}
\hline Variables & Factor I & Factor II & Factor III & $\mathbf{h}_{\mathbf{j}}^{2}$ \\
\hline 1 EQ: GENERAL MOOD & $\mathbf{0 , 7 1 3}$ & 0,185 & $+0,071$ & 0,718 \\
2 EQ: INTER-PERSONAL & $\mathbf{0 , 7 1 1}$ & $-0,025$ & $-0,017$ & 0,478 \\
3 LCI: INTERNAL CONTROL & $\mathbf{0 , 6 8 4}$ & $-0,027$ & $-0,064$ & 0,408 \\
4 LCI: AUTONOMY & $\mathbf{0 , 6 4 2}$ & 0,115 & $+0,112$ & 0,590 \\
5 EQ: INTRA-PERSONAL & $\mathbf{0 , 6 3 6}$ & $\mathbf{0 , 2 9 2}$ & $+0,170$ & 0,828 \\
6 EQ: ADAPTABILITY & $\mathbf{0 , 5 1 2}$ & $-0,155$ & $+\mathbf{0 , 4 9 6}$ & 0,718 \\
7 SOC: MEANINGFULNESS & $\mathbf{0 , 3 0 0}$ & $\mathbf{0 , 2 9 4}$ & $+0,268$ & 0,472 \\
8 POI: SELF-ACTUALISATION & $\mathbf{0 , 0 6 5}$ & $\mathbf{0 , 6 7 3}$ & $-0,053$ & 0,462 \\
9 POI: VALUE SYSTEMS & 0,019 & $\mathbf{0 , 4 5 8}$ & $+0,076$ & 0,251 \\
10 EQ: STRESS MANAGEMENT & 0,168 & $-0,223$ & $+\mathbf{0 , 8 1 2}$ & 0,735 \\
11 LCI: EXTERNAL CONTROL & 0,135 & $-0,105$ & $-\mathbf{0 , 6 5 0}$ & 0,389 \\
12 SOC: MANAGEABILITY & 0,136 & 0,244 & $+\mathbf{0 , 6 1 1}$ & 0,690 \\
13 SOC: COMPREHENSION & 0,134 & $\mathbf{0 , 0 8 0}$ & $+\mathbf{0 , 5 5 3}$ & $\mathbf{0 , 4 6 0}$ \\
\hline
\end{tabular}

Note. MSA $=0,869$

Bartlett's Test of Sphericity

Approximate $\chi^{2}(\mathrm{df}=78)=1480,561 ; \mathrm{p}<0,001$

Factor 3 has been reflected

\section{EQ Intra-personal}

This composite scale measures the degree to which a person is aware of his/her inner self and includes the following EQ- $\mathrm{i}^{\mathrm{r}}$ facet scales: Emotional Self-awareness, Assertiveness, Selfregard, Self-actualisation and Independence. A person who scores high on this scale is in touch with his/her feelings, feels good about himself/herself and feels positive about what he/she is doing. He/she can express his/her feelings, is independent, strong and confident in disclosing his/her ideas and beliefs (Bar-On, 1997).
EQ Adaptability

This scale determines to what extent a person is able to cope with environmental demands by effectively evaluating and dealing with problematic situations. The following facet scales are included in this scale: Problem Solving, Reality Testing and Flexibility (Bar-On, 1997).

\section{SOC Meaningfulness}

This scale measures the extent to which a person feels that life makes sense emotionally rather than cognitively (Antonovsky, 1993).

From the foregoing it is evident that Factor 1 is a broad and complex factor. Psychological Adjustment probably fits the profile best of all (Bradburn, 1969; Compton, 2001; Cowen, 1994).

Factor 2 has moderate to low loadings on the following scales: POI Self-actualisation, POI Value Systems, SOC Meaningfulness, and EQ Intrapersonal.

A brief exposition will now be given of the various scales with moderate to low loadings on Factor 2.

\section{POI Self-actualisation}

This scale relates to self-actualisation in the inter-personal sphere (Bloxom, 1972).

\section{POI Value Systems}

This scale deals with what an individual holds dear or important to himself/herself, i.e. the values of a self-actualised person (Schulz, 1994; Shostrum, 1964; Shostrum, 1974).

\section{SOC Meaningfulness}

This scale concerns the extent to which a person feels that life makes sense emotionally to him/her (Antonovsky, 1993).

\section{EQ Intra-personal}

This scale has already been described earlier in this section.

From the foregoing it is clear that Factor 2 relates to selfactualisation. It is therefore identified as Self-actualisation.

Factor 3 has moderate to high loadings on the following measures: EQ Adaptability, EQ Stress Management, LCI External Control (negative), SOC Manageability, and SOC Comprehension.

A brief exposition will now be given of the various scales listed above.

\section{EQ Adaptability}

This scale has already been described earlier in this section.

\section{EQ Stress Management}

This scale consists of the Stress Tolerance and Impulse Control subscales of the EQ-i. Persons with high scores on this scale are calm and work well under pressure. They can deal effectively with tasks that are stressful or anxiety provoking or that contain an element of danger (Bar-On, 1997, p.45).

\section{LCI External Control}

Persons with high scores on this scale believe that random or fortuitous events, fate, Lady Luck and certain influential people are responsible for their behaviour. They are convinced that the reinforcement of their behaviour has nothing to do with their own achievements, abilities and dedication (Rotter, 1966).

\section{SOC Manageability}

SOC Manageability refers to a person's perception that a particular situation is manageable, i.e. that the necessary resources are available and adequate to control the situation (Antonovsky, 1993). 


\section{SOC Comprehension}

Persons with high scores on this scale have a clear perception of the stimuli encountered in a particular situation. They see the stimuli as ordered and consistent, and the situation as well structured. Their perceptions thus make cognitive sense (Antonovsky, 1993).

From the foregoing it is clear that Factor 3 is concerned with Stress Management.

The intercorrelations between the three factors are given in Table 11.

TABLE 11

FACTOR CORRELATION MATRIX

\begin{tabular}{lccc}
\hline Factor & 1 & 2 & $3^{*}$ \\
\hline 1 & 1,000 & 0,381 & $+0,599$ \\
2 & 0,381 & 1,000 & $+0,382$ \\
$3^{*}$ & $+0,599$ & $+0,382$ & 1,000 \\
\hline
\end{tabular}

Note.

Factor $1=$ Psychological Adjustment

Factor 2 = Self-actualisation

Factor 3 = Stress Management

*Factor 3 has been reflected.

From Table 11 it is clear that Psychological Adjustment and Stress Management are substantially correlated $(r=0,599 ; \mathrm{p}<0,001)$. Self-actualisation is positively correlated with Psychological Adjustment $(\mathrm{r}=0,381 ; \mathrm{p}<0,001)$ and also with Stress Management $(r=0,382 ; p<0,001)$. It would thus appear that there is a single second-order factor underlying the correlations referred to.

Accordingly the eigenvalues of the matrix of factor intercorrelations were calculated. The obtained eigenvalues are given in Table 12.

TABLE 12

EIGENVALUES OF FACTOR INTERCORRELATION MATRIX

\begin{tabular}{lcc}
\hline Root & Eigenvalue & $\begin{array}{c}\text { Cummulative } \\
\text { percentage of variance }\end{array}$ \\
\hline 1 & 1,905 & $63,5 \%$ \\
2 & 0,748 & $88,4 \%$ \\
3 & 0,347 & $100,0 \%$ \\
\hline Trace & 3,000 & \\
\hline
\end{tabular}

Table 12 shows that there is only one eigenvalue greater than unity, and that it accounts for $63,5 \%$ of the total variance. Accordingly one factor was extracted and is given in Table 13.

TABLE 13

SECOND-ORDER FACTOR MATRIX

\begin{tabular}{lcc}
\hline Variables & Factor I & $\mathbf{h}_{\mathbf{j}}^{2}$ \\
\hline 1 Psychological Adjustment & 0,901 & 0,812 \\
2 Self-actualisation & 0,423 & 0,179 \\
3 Stress Management & 0,717 & 0,514 \\
\hline
\end{tabular}

From Table 13 it is clear that Factor 1 (Psychological Adjustment) has the highest loading on the second-order factor $(0,901)$. Stress Management also has a high loading on this factor $(0,717)$. Selfactualisation has a moderate loading $(0,423)$ on this factor. The obtained second-order factor thus represents Psychological Wellness in the fullest sense of the concept (Adams, Bezner, Drabbs, Zambarano \& Steinhardt, 2000; Kozma, Stones \& McNeil, 1991; Moomal, 1999; Walsh \& Shapiro, 1983).

\section{DISCUSSION}

The construct validity and metrical properties of the LCI The factor analysis that was conducted confirmed the threefactor-structure of the LCI that was previously found (Schepers, 2005). The obtained factors were interpreted as Autonomy, External Control and Internal Control, and is in keeping with the theoretical basis of the LCI. The construct validity of the scale was therefore confirmed. It was found that External Control and Internal Control are essentially uncorrelated $(\mathrm{r}=-0,160)$, and not merely bipolar opposites. Autonomy and Internal Control are substantially correlated $(\mathrm{r}=0,563)$, and share $31,7 \%$ common variance. However, the reliability of Autonomy is 0,880 , therefore its specific variance is $56,3 \%(0,880-0,317=0,563)$. Both scales therefore make a contribution of their own.

Cronbach alphas of 0,$880 ; 0,871$ and 0,822 were obtained in respect of Autonomy, External Control and Internal Control respectively. These reliabilities are highly acceptable from a measurement point of view.

No items were rejected during the item analysis phase, however, it became clear that items 11 and 17 should be included in the category of Internal Control rather than External Control and that item 11 should be reflected. Furthermore, it was clear that items 26, 62 and 78 should be revised (de Bruin, 2004, pp. 1920). All these changes were made in the fourth edition (2003) of the LCI.

The convergent validity of the LCI

From the joint analysis of the LCI, the EQ-I, the POI and the SOC three common factors were obtained which were interpreted as Psychological Adjustment, Self-actualisation, and Stress Management.

Psychological Adjustment emerged as a strong factor with high loadings on EQ General Mood, EQ Interpersonal, Internal Control, Autonomy, EQ Intra-personal and EQ Adaptability, and a low loading on SOC Meaningfulness.

Self-actualisation manifested with high loadings on POI Selfactualisation and POI Value Systems, and low loadings on SOC Meaningfulness and EQ Intra-personal.

Stress Management also emerged as a strong factor with high loadings on EQ Stress Management, SOC Manageability, SOC Comprehension, EQ Adaptability, and a negative loading on External Control.

All three factors are mutually correlated and define a broad factor which is best defined as Psychological Wellness.

From the foregoing it should be clear that the meaning of the three constructs of locus of control should be extended to incorporate their association with the measures listed above.

Persons with high scores on Internal Control and Autonomy are convinced that success in life depends on their own abilities and dedication. They are sure that they can overcome adverse circumstances and solve complex problems on their own. They are usually cheerful, positive, hopeful and optimistic. They are responsible and dependable individuals with good social skills. 
They interact and relate well with others (Bar-On, 1997). They are in touch with their feelings and feel good about themselves and what they are doing. They can readily express their feelings, are independent, strong and confident in disclosing their ideas and beliefs. They are able to cope with environmental demands and can effectively deal with problematic situations. Life makes sense to them emotionally (Antonovsky, 1993). They are fully self-actualised individuals (Shostrum, 1974). They are calm and work well under pressure. They can deal effectively with tasks that are stressful or anxiety-provoking or that contain an element of danger (Bar-On, 1997, p.45).

By contrast with the foregoing, persons who are high on External Control believe that random or fortuitous events, fate, Lady Luck and certain influential people are responsible for their destiny in life. They are unable to manage stress in any shape or form. They are the direct antithesis of persons who are high on Internal Control and Autonomy.

From the foregoing it should be clear that the third edition (1999) of the LCI shows great promise indeed. Minor changes in respect of three items seem to be indicated, and a final set of norms needs to be prepared.

\section{ACKNOWLEDGEMENTS}

I hereby wish to thank all the members of the Statistical Consultation Service of the University of Johannesburg for all the hours of computational work done for me. I value it very highly.

A special word of thanks to Annetjie Boshoff and her assistant Afton Walters for the typing of the manuscript. Nobody can type tables better than Annetjie.

\section{REFERENCES}

Adams, T.B., Bezner, J.R., Drabbs, M.E., Zambarano, R.J. \& Steinhardt, M.A. (2000). Conceptualisation and measurement of the spiritual and psychological dimensions of wellness in a college population. Journal of American College of Health, 48 (4), 165-173.

Antonovsky, A. (1993). The structure and properties of the sense of coherence scale. Social Science and Medicine, 36 (6), 725-733.

Bar-On, R. (1997). BarOn Emotional Quotient Inventory Technical Manual. Toronto: MultiHealth System Inc.

Bloxom, B. (1972). The Personal Orientation Inventory. In O.K. Buros (Ed.), The Seventh Mental Measurements Yearbook, 290292). New Jersey: Gryphon Press.
Bradburn, N.M. (1969). The structure of psychological wellbeing. Chicago: Aldine Publishing Company.

Compton, W.C. (2001). Towards a tripartite factor structure of mental health: subjective well-being, personal growth and religiosity. The Journal of Psychology, 135 (5), 486-500.

Cowen, E.L. (1994). The enhancement of psychological wellness: challenges and opportunities. American Journal of Community Psychology, 22 (2), 149-179.

De Bruin, G.P. (2004). Problems with the factor analysis of items: Solutions based on item response theory and item parcelling. SA Journal of Industrial Psychology, 30 (4), $16-26$.

Kaiser, H.F. (1961). A note on Guttman's lower bound for the number of common factors. British Journal of Statistical Psychology, 14 (1), 1.

Knapp, R. (1976). Handbook for the Personal Orientation Inventory. San Diego, Calif: Edits.

Kozma, A., Stones, M.J. \& McNeil, J.K. (1991). Psychological wellbeing in later life. Toronto and Vancouver: Butterworths Canada Ltd.

Linacre, J.M. (2003). Winsteps. Chicago: MESA Press.

Moomal, Z. (1999). The relationship between meaning in life and mental wellbeing. S.A. Journal of Psychology, 29 (1), 3641.

Rasch, G. (1960). Probalistic models for some intelligence and attainment tests. Copenhagen: Danmarks Paedagogiske Institut.

Rotter, J.B. (1966). Generalized expectancies for internal versus external control of reinforcement. Psychological Monographs, 80, No 1 (Whole No. 609).

Schepers, J.M. (2004). Overcoming the effects of differential skewness of test items in scale construction. S.A. Journal of Industrial Psychology, 30 (4), 27-43.

Schepers, J.M. (2005). The construction of a normative scale of Locus of Control. Journal of Industrial Psychology, 31 (3), $1-11$.

Schulz, G.M. (1994). Reliability and validity of the Personal Orientation Inventory in South Africa. Pretoria: Unisa.

Shostrom, E.L. (1964). An Inventory for the measurement of SelfActualisation. Educational and Psychological Measurement, 24 (2), 207-218.

Shostrom, E.L. (1974). Manual for the Personal Orientation Inventory. (rev. ed.). San Diego, California: EDITS.

Walsh, R. \& Shapiro, D.H. (1983). Beyond health and normality: Explorations of exceptional psychological well-being. New York: Van Nostrand Reinhold Company Inc.

Wolman, B.B. (1973). Dictionary of behavioral science. New York: Van Nostrand Reinhold Company. 